University of New Hampshire

University of New Hampshire Scholars' Repository

\title{
The News You Choose: News Media Preferences Amplify Views on Climate Change
}

Jessica L. Bolin

Boston College, bolin@bc.edu

Lawrence C. Hamilton

University of New Hampshire, lawrence.hamilton@unh.edu

Follow this and additional works at: https://scholars.unh.edu/soc_facpub

Part of the Sociology Commons

\section{Comments}

This is an Author's Original Manuscript of an article published by Taylor \& Francis in Environmental Politics in 2018, available online: https://dx.doi.org/10.1080/09644016.2018.1423909

\section{Recommended Citation}

Bolin, J.L. \& L.C. Hamilton. 2018. "The news you choose: News media preferences amplify views on climate change." Environmental Politics doi: 10.1080/09644016.2018.1423909

This Article is brought to you for free and open access by the Sociology at University of New Hampshire Scholars' Repository. It has been accepted for inclusion in Sociology Scholarship by an authorized administrator of University of New Hampshire Scholars' Repository. For more information, please contact Scholarly.Communication@unh.edu. 
Authors' draft, January 2018

Final version published in Environmental Politics (2018) doi: 10.1080/09644016.2018.1423909

available online at http://www.tandfonline.com/10.1080/09644016.2018.1423909

\title{
The news you choose:
}

News media preferences amplify views on climate change

Jessica L. Bolin

bolinj@bc.edu

Department of Sociology

Boston College

Chestnut Hill, MA 02467

Lawrence C. Hamilton

Lawrence.Hamilton@unh.edu

Department of Sociology

University of New Hampshire

Durham, NH 03824

\begin{abstract}
How do choices among information sources reinforce political differences on topics such as climate change? Environmental sociologists have observed large-scale and long-term impacts from news media and think-tank reports, while experimental science-communication studies detect more immediate effects from variations in supplied information. Applying generalized structural equation modeling (GSEM) to recent survey data, previous work is extended to show that political ideology, education, and their interaction predict news media information choices in much the same way they predict opinions about climate change itself. Consequently, media information sources serve as intervening variables that can reinforce and, through their own independent effects, amplify existing beliefs about climate change. Results provide empirical support for selective exposure and biased assimilation as mechanisms widening political divisions on climate change in the United States. The findings fit with the reinforcing spirals framework suggesting partisan media strengthens climate change beliefs which then influences subsequent use of media.
\end{abstract}

Keywords: reinforcing spirals; climate change; ideology; polarization; Fox News; public radio 


\section{Introduction}

A U.S. Gallup poll in 2001 found that $61 \%$ believed human activities are the cause of climate change. Over the next decade this percentage dropped into the low 50s; after 2010 it drifted back up in 2016 to a new high point — but at $65 \%$, it stood just four points higher than fifteen years earlier (Saad and Jones 2016). During that decade and a half, however, scientists reported 15 of the 16 warmest years on record (NASA 2016). At a time when scientists have identified critical threats linked to changing climate - rising sea levels, melting ice caps and extreme weather events of increasing frequency and severity, along with challenges to ecosystems, fresh water and food supplies - the basic reality of anthropogenic climate change remains an issue of political contention in the United States.

Divisions over anthropogenic climate change intensified since the 2008 and 2012 presidential elections. In 2008, almost identical proposals for a cap-and-trade plan left little distinction between Republican candidate, John McCain, and Democratic candidate, Barack Obama (Davenport 2016). In contrast, climate change became a distinguishing, although underreported, issue in the 2016 presidential election where a stark contrast existed between Republicans and Democrats regarding both the reality and the need for action. Social scientists have explored factors that characterize or might help to explain this polarization in many different studies (e.g., McCright et al. 2014, Dunlap et al. 2016, Hamilton 2016a, Carmichael and Brulle 2017, Kim and Urpelainen 2018).

Countering efforts from scientists and environmentalists to educate the public on concepts and evidence of climate change since it gained prominence in the early 1990s, conservative elites and organizations saturated public discourse with arguments for rejection (Jacques et al. 2008, Dunlap and McCright 2015). Over the last decade, science communicators achieved limited success in gradually changing perceptions across party lines (Hamilton 2016a). Research suggests, however, that individuals still often acquire, credit, and retain information selectively depending on whether it supports or conflicts with their existing beliefs-processes variously referred to as confirmation bias, biased assimilation, or motivated reasoning (Lord et al. 1979, Munro and Ditto 1997, Taber and Lodge 2006, Corner et al. 2012). Moreover, to avoid disconfirming information, individuals also prefer information sources that reinforce their predispositions (Slater 2007, Zhao 2009, McCright 2011, Hamilton 2014, Feldman et al. 2014, Jasny et al. 2015), or keep them informed of party and leadership positions (Darmofal 2005, Brulle et al. 2012) — patterns of selective exposure. Education can aid these processes by mediating media use (Zhao 2009, Zhao et al. 2011, Ehret et al. 2017), and interacting with political identity to further polarization on politicized issues (Hamilton 2008, 2011, Hamilton and Keim 2009, Hamilton et al. 2015b, McCright and Dunlap 2011). Whether selecting or evaluating information, media sources play a critical role in maintaining the division over anthropogenic climate change (Jasny et al. 2015, Carmichael et al. 2017).

Here, we examine that role by analyzing preferred information sources as variables that might intervene between political identity and climate change beliefs. In this intervening role, information choice reinforces existing prejudices regarding climate change. However, information choice may also explain some variation on its own, which could make it something that not just reinforces but amplifies divisions. In contrast with experimental studies of science communication, we draw on nonexperimental, single-state survey data from six individual polls conducted over a 10-month period. We apply generalized structural equation modeling (GSEM) to characterize the background predictors of information source choices, the direct effects of information source on climate change beliefs, and the indirect effects of background 
characteristics on beliefs through preferred information sources. Confirmation bias, selective exposure, and related theories suggest testable hypotheses that ideology, education, and their interaction could influence information choices in much the same way they do for climate change beliefs, so that ideological and education effects operate both directly and indirectly. One other key hypothesis is that information choices exhibit independent effects of their own, further widening climate change divisions.

\section{Political polarity of climate change}

Since the 1970s, American politics experienced increasing polarization on racial, cultural, and social welfare issues (Layman et al. 2006). Despite largely unified scientific support, climate change has become one of the most divisive issues among the general public. Early studies of climate change perceptions presumed the problem was a lack of factual information, which could be supplied. Research finds only partial support for this simple information deficit hypothesis, however (Hamilton 2008, Hart and Nisbet 2011, Kahan et al. 2012, Hamilton et al. 2012, Zhou 2016, Ehret et al. 2017). Although education and scientific literacy have detectable effects, compatible with information deficit, political indicators exhibit stronger and more consistent effects.

In the United States, political party or ideology are now the dominant predictors of perceptions about anthropogenic climate change, as well as many other environment and science-related issues (e.g., Hamilton 2008, 2011, 2014, McCright and Dunlap 2011, McCright et al. 2014). One feature of the evolving conservative landscape has been the advance of the Tea Party movement since 2009 (McCright et al. 2014). Acknowledging this change, some researchers elaborate the traditional Democrat/Independent/Republican party model by distinguishing supporters of the Tea Party movement as a fourth 'party' (Hamilton and Saito 2015, Shao 2016). This four-party scheme adds explanatory power across many issues, with Tea Party supporters consistently expressing more extreme views compared with non-Tea Party Republicans. Issues exhibiting a clear four-party gradient include not only climate change but gun control, abortion, the death penalty, evolution, and trust in scientists on various topics including vaccines (Hamilton 2015, Hamilton and Saito 2015, Hamilton et al. 2015a). Perceptions about specific aspects of climate change — such as sea level rise, melting polar ice caps, and animal extinction - also display political and ideological gradients. Age and gender have somewhat weaker effects on environmental and science question responses. After politics, education proves to be the most consistent predictor. Education often interacts with politics, however: education shows positive effects on science acceptance among liberals and moderates (or Democrats and Independents), but near-zero or even negative effects among the most conservative (or Tea Party supporters) (e.g., Hamilton 2008, 2011, Hamilton and Saito 2015).

As a result of this interaction, better-educated partisans stand the farthest apart on climate change. This occurs not only with conventional indicators for education and ideology (e.g., McCright and Dunlap 2011, Hamilton 2008, 2011, Hamilton and Saito 2015), but also for other information indicators such as objectively-assessed science literacy (Hamilton et al. 2012, Drummond and Fischhoff 2017) or numeracy (Kahan et al. 2011), and also subjectively-assessed understanding (Hamilton 2011, McCright and Dunlap 2011). Scholars explain such interactions in top-down terms of more educated or information-rich partisans being more aware of party and leadership positions, or in bottom-up terms of educated partisans more actively filtering information to support their beliefs. Although both types of explanations are logical and may 
operate together, their processes tend to be inferred rather than observed in the context of survey interaction effects.

On average, higher levels of education correlate with greater concern about environmental problems, consistent with the information deficit model. However, stronger effects from political identity, and interactions between education and political identity, suggest selective exposure and similar processes play a greater role which helps to explain why science literacy is helpful but not sufficient in raising public consensus on climate change. Many studies have now confirmed interactions of this general type (Hamilton 2008, 2011, Hamilton and Keim 2009, Hamilton et al. 2012, 2015b, Kahan et al. 2011, McCright and Dunlap 2011, Shao et al. 2014, Kahan 2015, Drummond and Fischhoff 2017). Such interactions also affect other environment or science-related issues besides the climate, including evolution, vaccines, scientists, or environmental protection (Hamilton et al. 2010, 2015a, Hamilton and Safford 2015, Hamilton and Saito 2015). In most of these studies, interpretations of the interaction results have mentioned (but not analyzed) the selective acquisition of information.

\section{The role of news media \\ Elite cues}

Several theories offer insight into the influential role of American news media. The elite cues hypothesis suggests individuals form opinions based on cues given by elites with whom they identify. Brulle and colleagues (2012) investigate five diverse factors potentially affecting Americans' concern for climate change and find substantial support for elite cues. They argue that, while media itself is influential, it more importantly provides viewers with elite cues that influence their position on particular issues (2012, p. 176). Similarly, Darmofal (2005) identifies political elites as highly influential in challenging expert opinion, regardless of the argument's validity. Guber (2013) notes the role of information in ideological party sorting as people become aware of party elite positions.

Other studies look specifically at the role of cable television news (Zhao 2009, Krosnick and MacInnis 2010, Stroud 2011, Feldman et al. 2012). For example, regular viewers of Fox News hear more dismissive arguments against anthropogenic climate change, and are less likely to accept its reality, compared with viewers of other networks (Krosnick and MacInnis 2010, Feldman et al. 2012). Although public radio is sometimes perceived as liberal in orientation, it carries local and national content with a broad informative rather than political focus, including many conversations with scientists in their fields of expertise. Hamilton (2014) finds New Hampshire public radio audiences are significantly more inclined than consumers of other local news to trust scientists and accept the scientific consensus on anthropogenic climate change. Preference for public radio as an information source consequently coincides to some degree with preference for and exposure to ordinary science (Hamilton 2014). Using National Public Radio as a measure for non-conservative media, Feldman and colleagues (2014) find the effects from ideology are much stronger, and effects from education much weaker, for conservative media use compared to non-conservative media. Additionally, studies comparing the content of conservative and non-conservative news media find substantial discrepancies in how climate change is framed in reporting (Feldman et al. 2012, Nisbet 2009).

A national survey during the 2016 election campaign found examples of such selectivity in trusted authorities on climate science. Among Trump supporters, conservative Fox News was the second most trusted source for information about climate change: $61 \%$ trust scientists while $49 \%$ trust the conservative news source (Hamilton 2016b). Furthermore, supporters of the 
Republican presidential candidate were least trusting of political leaders in their party for climate change information (Hamilton 2016b). Although Trump's anti-establishment rhetoric may contribute to these differences, his supporters trust Fox News more than religious leaders, friends, or websites. These results further support characterizations of Fox News as influential, providing elite cues that link viewers' political identity with specific beliefs about climate change and other science topics.

\section{Reinforcing spirals}

The reinforcing spirals framework connects ideas of selective exposure and biased assimilation: individuals seek out information sources that reaffirm biases while strengthening their position through repeated exposure to those sources (Slater 2007). Individuals use motivated reasoning to process information in a biased manner that reinforces their predispositions (Taber and Lodge 2006, Feldman et al. 2014).

One recent study explores this process using a two-wave survey to test the effects of media selectivity. Feldman and colleagues (2014) apply the reinforcing spirals framework in their study on selective exposure and global warming attitudes. Utilizing a longitudinal design, they conduct two waves to test the long-term effects of news media in shaping beliefs and policy support. Their model demonstrates the reinforcing processes of partisan media influencing climate change certainty and policy support which in turn drives subsequent media use. They found conservative or non-conservative media use at Wave 1 increased subsequent media use at Wave 2. Additionally, positions on climate change certainty and policy support for mitigation strengthened from the first to second wave. As a result, Feldman and colleagues argue partisan media use and position on climate change reinforce one another through indirect effects.

Furthermore, conservative media use lowers acceptance of the reality and policy implications of global warming, whereas the opposite is true for non-conservative media use. Differences between conservative and non-conservative media suggest the former acts as an 'echo chamber' making it more susceptible to reinforcement (Feldman et al. 2014). Feldman and coauthors describe the spiraling effect regarding Fox News:

They provide consistent political messaging, which influences political beliefs, and these beliefs in turn drive people back to the media which support these beliefs and away from media that do not, in a repeating cycle. (p. 604)

Additionally, studies find conservatives are more susceptible to reinforcing spirals compared to liberals (McCright 2011, McCright and Dunlap 2011). McCright suggests this is because climate change poses a greater threat to the existing industrial economic system than previous environmental problems, leading conservatives to engage in 'strong system-justifying attitudes' (2011, p. 249). The polarization observed among conservatives becomes apparent when exposed to information that contradicts existing beliefs.

\section{Hypotheses}

Considering the politicization of climate change and cable news, we expect to find that demographic characteristics and political identity affect information source preferences in ways parallel to their effects on climate change views. That is, preferred news media and belief in anthropogenic climate change will be similarly affected by age, sex, education, political identity, and the interaction between education and politics. Consequently, we model source preferences as intervening variables influenced by background, but capable also of further effects on beliefs 
about climate. We anticipate political identity will exhibit stronger relationships to more politicized sources; specifically, Fox News will be the preferred information source for conservatives and public radio for liberals. Choice of politicized news media would be an obvious sign of selective exposure, which in itself could reinforce politically-linked predispositions to reject anthropogenic climate change. We expect education, and its interaction with political identity, will exhibit polarizing effects for more politicized sources. Finally, we hypothesize that media preferences will show independent effects of their own on beliefs about climate, which results in even wider divisions.

\section{Methods}

Data

The data used in this study are 3,852 interviews conducted in six individual surveys over a period from July 2015 to May 2016 for the Granite State Poll (GSP). The University of New Hampshire's Survey Center operates this statewide random-sample telephone survey, obtaining a mean response rate of 19 percent over the study period (definition 4, AAPOR 2006).

Interviewers record demographic information including sex, age, and education. In addition to demographic questions, the poll asks about a variety of political, environmental, and news media topics.

The GSP includes three standard questions gauging political identity. Interviewers ask respondents for which party they are registered to vote and, separately, whether they support the Tea Party movement. These two questions together provide a four-party political indicator that has been successfully tested in several studies (Hamilton and Saito 2015; Hamilton et al. 2015a). A third political question asks respondents to characterize their ideology, from liberal to conservative. Interviewers also ask whether respondents think that climate change 'is happening now, caused mainly by human activities,' 'happening now, but caused mainly by natural forces,' or 'not happening now.' Some respondents say they do not know, or give no answer. These particular surveys also carried questions about the frequency with which the respondent uses news media sources including New Hampshire Public Radio, a local TV station, and Fox News. Response distributions for the news media and climate change questions are charted in Figure 1. Table 1 gives the wording for these and other questions, together with response percentages and codes later used for statistical modeling. 


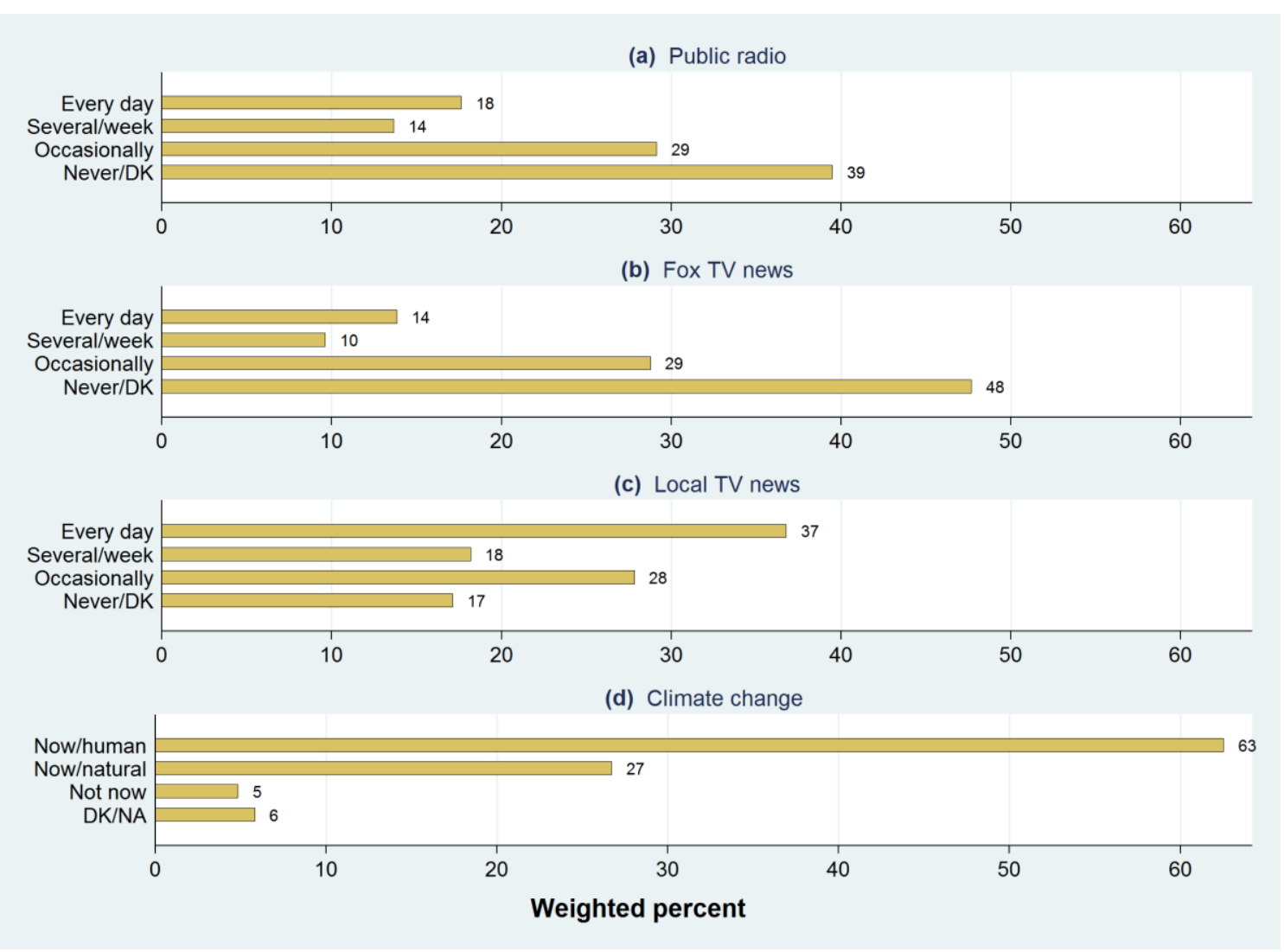

Figure 1. Frequency of news viewership by information source (a through c) - Fox News, public radio, and local TV news - and distribution of climate change beliefs (d). Weighted percentages from Granite State Polls conducted during 2015-2016.

All graphs and analyses reported here employ probability weights, which accomplish minor adjustments to better represent the population of New Hampshire. The Granite State Poll weights adjust for known design bias (related to household size and number of telephones), and minor differences between the samples and state population with regard to geography, gender and age.

New Hampshire residents are politically divided on climate change, much like the nation as a whole (Hamilton et al. 2015b). More than half think that climate change is happening now, caused mainly by human activities. Only a third think that the climate is changing, but mainly from natural forces. Overall, $90 \%$ of respondents believe climate change is happening nowwhether from natural or human causes - compared to $10 \%$ who answered that climate change is not happening or do not know. Figure 1d thus shows broad agreement that climate change is happening, although there are sharp divisions over the cause.

Of the three media choices mentioned in our surveys, respondents viewed local TV news most heavily. Over half of respondents report watching at least several times a week. Public radio has the second largest audience with $31 \%$ listening regularly, followed by $24 \%$ who regularly watch Fox News. A 2013 Gallup poll reported that 55\% of Americans use television as their main source of news followed by the internet (21\%) and radio (6\%) (Saad 2013). Differences between national and New Hampshire news preferences likely reflect the more specific information sources asked about in GSP surveys. 
Table 1. Definitions of variables from Granite State Poll (GSP) survey of New Hampshire residents conducted from July 2015 to May $2016(n=3,852)$.

\section{Climate change question}

Climate Change: Which of the following three statements do you think is more accurate? (Answers rotated)

Don't Know/Not Sure (coded 0;6\%)

Climate change is not happening now (coded $0 ; 5 \%$ )

Climate change is happening now, but caused by natural forces (coded $0 ; 27 \%$ )

Climate change is happening now, caused mainly by human activities (coded $1 ; 63 \%$ )

\section{News media question}

Fox News: How often, if ever, do you watch Fox News?

Never/Don't Know (coded 0; 48\%)

Occasionally (coded $0 ; 29 \%$ )

Several times a week (coded $1 ; 10 \%)$

Every day (coded $1 ; 14 \%$ )

Public Radio News: How often, if ever, do you listen to New Hampshire Public Radio?

Never/Don't Know (coded 0; 40\%)

Occasionally (coded $0 ; 29 \%$ )

Several times per week (coded $1 ; 14 \%)$

Every day (coded $1 ; 18 \%$ )

Local TV News: How often, if ever, do you watch WMUR, Channel 9 News?

Never/Don't Know (coded 0; 17\%)

Occasionally (coded $0 ; 28 \%$ )

Several times per week (coded $1 ; 18 \%)$

Every day (coded $1 ; 37 \%$ )

Respondent background characteristics

Ideology: In politics, do you generally think of yourself as a liberal, a moderate, or a conservative?

Liberal (coded $-2 ; 21 \%$ )

Moderate Liberal (coded $-1 ; 21 \%$ )

Moderate (coded 0;14\%)

Moderate Conservative (coded $1 ; 24 \%$ )

Conservative (coded 2; 19\%)

Party: Are you registered as a Democrat, Independent, Republican or something else? Would you say you lean towards supporting or opposing the Tea Party movement?

Democrat (coded $-1 ; 42 \%)$

Independent (coded $0 ; 16 \%)$

Republican (coded 1;24\%)

Tea Party (coded $2 ; 18 \%)$

Age: (mean 48 years, range $18-96$ years)

Sex: $\quad$ Male (coded 0; 49\%)

Female (coded as $1 ; 51 \%$ )

Education: What is the highest grade in school, or level of education that you've completed and got credit for?

High School or less (coded $-1 ; 19 \%)$

Some College (coded 0; 24\%)

College Graduate (coded 1; 35\%)

Postgraduate (coded 2; 23\%)

Note. Interviewers rotated the order of response choices. Probability-weighted proportions or means without missing data. 


\section{Variables}

Although the positions that climate is not changing, or that it is changing but for natural reasons, appear to be logically distinct, survey data suggest that they are socially less distinct. People might easily shift between them, as public arguments often do. Those holding the contrary position that climate is changing due mainly to human activities (anthropogenic climate change), by contrast, appear socially more distinct from both the not-changing and naturally-changing groups. Moreover, this position uniquely corresponds to the overwhelming, evidence-based consensus among scientists. For purposes of this study, we therefore contrast those who believe in anthropogenic climate change (our now/human-caused response) with all other views on this topic. Our final endogenous variable is a $(0,1)$ indicator for belief in anthropogenic climate change. Additionally, the model incorporates information choices as intervening variables. The news media questions each offer four response choices, from 'never' to 'every day.' We also dichotomize these items for statistical modeling, grouping 'every day' and 'several times per week' responses together. Dichotomization makes the modeling results easier to interpret and compare. We also tested alternative versions (not shown) that retain the original ordinal coding, and confirmed that these obtain substantially similar results.

The exogenous variables are age, sex, education, political party, and political ideology. We treat education as ordinal rather than continuous to represent increments in professional qualification. The model incorporates political party as a fourth party based on findings that Tea Party supporters are distinct from non-Tea Party Republicans in important ways (Hamilton and Saito 2015, McCright et al. 2014, Shao 2016). Political party and ideology are individually strong predictors when included together in the model, even though support for the Tea Party movement has declined during the past several years mainly due to the funneling of party contributions to consultants rather than candidates (Bartlett 2013, Lipton and Steinhauer 2015). Lastly, the model incorporates interaction effects between political ideology and education reliably found in previous research (e.g., Hamilton 2011, 2016a, Hamilton et al. 2012, McCright and Dunlap 2011). We use political ideology rather than party in the interaction for better consistency going forward in an evolving political environment marked by erosion of Tea Party identification.

\section{Results}

Generalized structural equation modeling (GSEM) extends the well-known analytical framework of structural equation modeling (SEM). SEM originally encompassed only linear regression-type models, whereas GSEM permits logit, probit, and other type of models under a generalized linear modeling approach. Thus, GSEM (unlike SEM) allows us to estimate effects in structural equation models where endogenous variables are dichotomous or categorical — as with these climate and news-preference items. Like SEM, GSEM permits models with intervening variables so we can examine both direct and indirect effects. For the dichotomous endogenous variables studied here, we employ a logistic regression version (logit link function, Bernoulli distribution family).

Figure 2 depicts our structural equation model. To keep this readable, we draw in only the statistically significant effects, representing these as solid (positive) or dashed (negative) lines. The underlying statistical model includes all possible effects, however. In this model respondent age, sex, education, ideology, and education are exogenous. We also include an education $\times$ ideology interaction term among the exogenous predictors. Three media-use items indicating frequent attention to Fox News, public radio, or local TV news are included as 
intervening endogenous variables. The final endogenous variable indicates whether respondents think that climate change is happening now, caused mainly by human activities. The structural equation model involves four equations, as detailed with parameter estimates, standard errors, and significance test results in Table 2.

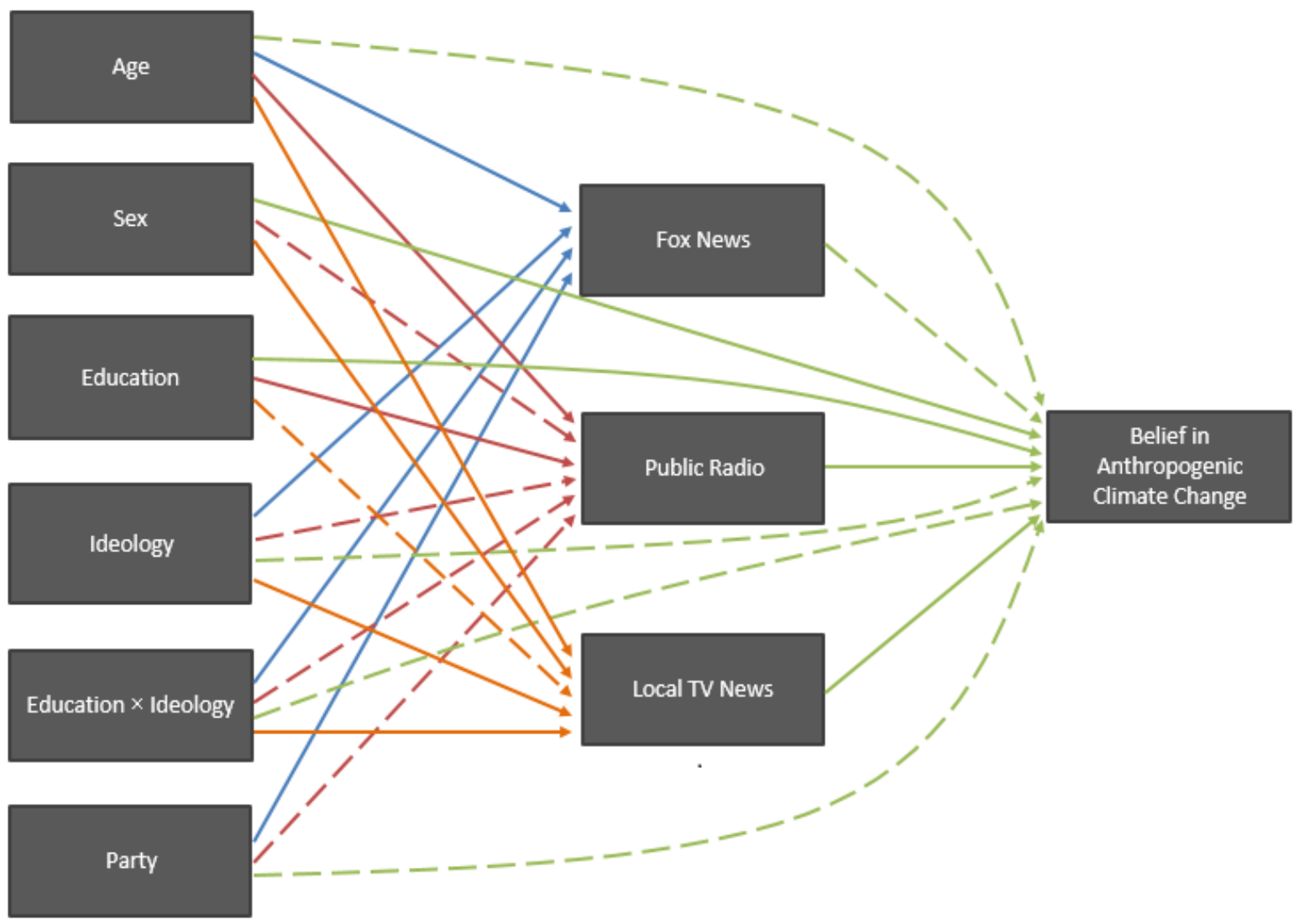

Figure 2. Path diagram showing significant relationships of the structural equation model found in Table 2. Solid lines represent a significant positive relationship between variables; dashed lines represent a significant negative relationship. 
Table 2. Results from generalized structural equation modeling using weighted logit regression $(n=$ 2,977).

\begin{tabular}{lcccc}
\hline Predictor & Fox News & Public Radio & Local TV News & Climate \\
\hline Age & $0.026(0.003)^{* * *}$ & $0.012(0.003)^{* * *}$ & $0.033(0.003)^{* * *}$ & $-0.017(0.003)^{* * *}$ \\
Sex & $0.055(0.113)$ & $-0.324(0.097)^{* *}$ & $0.419(0.090)^{* * *}$ & $0.235(0.109)^{*}$ \\
Party & $0.724(0.061)^{* * *}$ & $-0.213(0.055)^{* * *}$ & $0.056(0.049)$ & $-0.523(0.055)^{* * *}$ \\
Ideology & $0.294(0.055)^{* * *}$ & $-0.175(0.054)^{* *}$ & $0.074(0.044)$ & $-0.394(0.049)^{* * *}$ \\
Education & $-0.136(0.061)^{*}$ & $0.338(0.048)^{* * *}$ & $-0.223(0.045)^{* * *}$ & $0.210(0.053)^{* * *}$ \\
Ed $\times$ Ideo & $0.154(0.044)^{* * *}$ & $-0.123(0.036)^{* *}$ & $0.087(0.031)^{* *}$ & $-0.130(0.039)^{* *}$ \\
Fox News & & & & $-0.748(0.125)^{* * *}$ \\
Public Radio & & & & $0.497(0.122)^{* * *}$ \\
Local TV & & & & $0.322(0.115)^{* *}$ \\
Constant & $-2.839(0.212)^{* * *}$ & $-1.449(0.167)^{* * *}$ & $-1.365(0.153)^{* * *}$ & $1.298(0.184)^{* * *}$ \\
\hline Adjusted & 0.192 & 0.139 & 0.186 & 0.364 \\
Count $R^{2}$ & & & & \multirow{2}{*}{. } \\
\hline
\end{tabular}

Note. Model entries are unstandardized logit regression coefficients with standard errors in parentheses. ${ }^{*} p<0.05 ; * * p<0.01 ; * * * p<0.001$

All exogenous variables display statistically significant direct effects on climate beliefs, but political views - represented by party and ideology — are the strongest. Both ideology $(b=$ $-0.394, p<0.001)$ and party $(b=-0.523, p<0.001)$ effects confirm that the probability of belief in anthropogenic climate change decreases with conservatism. The main effect of education $(b=0.21)$ is positive, indicating that education increases the probability of belief in human-caused climate change among ideologically moderate respondents (ideology $=0$ ). The interaction between political ideology and education $(b=-0.13, p<0.01)$ indicates that the positive education-climate relationships is stronger (more positive) among moderate liberals and liberals; however, it becomes negative among the most conservative. Age has a negative effect on belief in anthropogenic climate change $(b=-0.017, p<0.001)$, and sex (female) a positive effect $(b=0.235, p<0.05)$, consistent with much previous research. Younger adults and women are more inclined to agree with the scientific consensus on anthropogenic climate change.

Differences in age and sex also influence news media preferences. Age has small, but consistent effects: older individuals attend more to all types of news. Sex has less consistent effects. It is the strongest predictor for local TV news audiences $(b=0.419, p<0.001)$ with women much more likely to regularly watch local TV news than men. In contrast, public radio audiences are slightly more likely to be male $(b=-0.324, p<0.01)$. Fox News viewership exhibits no significant gender difference $(b=-0.055)$.

Political ideology, party, and education effects highlight distinctions between audience demographics for Fox News, public radio, and local TV. Unsurprisingly, both party $(b=0.724, p$ $<0.001)$ and ideology $(b=0.294, p<0.001)$ significantly affect Fox News watching: it is highest among conservatives. Liberals more often listen to public radio, as demonstrated by the significant negative relationship with political party and ideology. Respondents with higher education are less likely to watch local TV news, but more likely to listen to public radio. Interestingly, education exhibits a significant but weak main effect on Fox News viewership. However, the significant interactions affecting all three news choices somewhat complicate this picture. 
Education $\times$ ideology interactions affecting all three news sources expand upon previous studies (Sears and Freedman 1967, Taber and Lodge 2006, Stroud 2011), establishing that ideological divergence among preferences grows wider with education. This is consistent with the selective exposure hypothesis: more educated individuals are demonstrably more selective in their information choices, and especially so regarding sources commonly seen as conservative (Fox News) or liberal (public radio) in outlook. These interactions are visualized by adjusted marginal plots in Figure 3. Both Fox News $(b=0.154, p<0.001)$ and public radio $(b=-0.123$, $p<0.001$ ) have relatively strong interaction effects, but opposite in sign. Fox News viewership increases with education among conservatives, whereas public radio listenership increases with education among liberals. Although the education $\times$ ideology effect on local TV news viewership $(b=0.087, p<0.01)$ is similar in shape to that for Fox News, it is much weaker.

(a) Fox TV news often

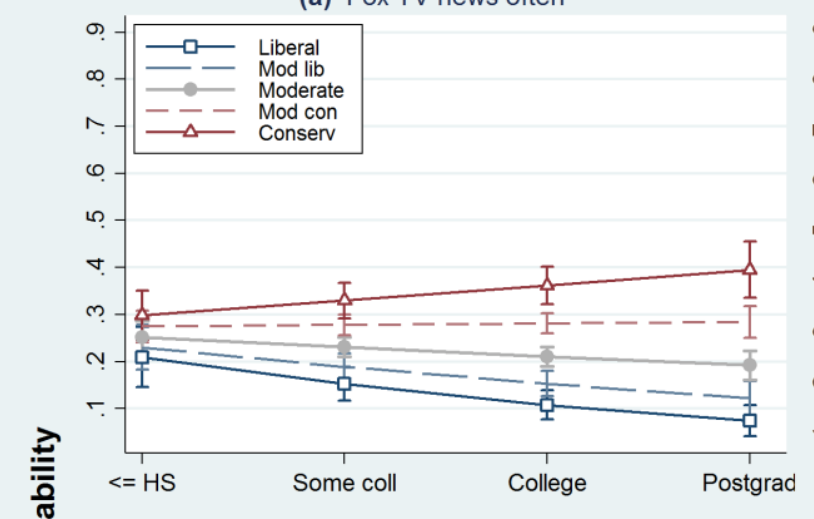

(c) Local TV news often

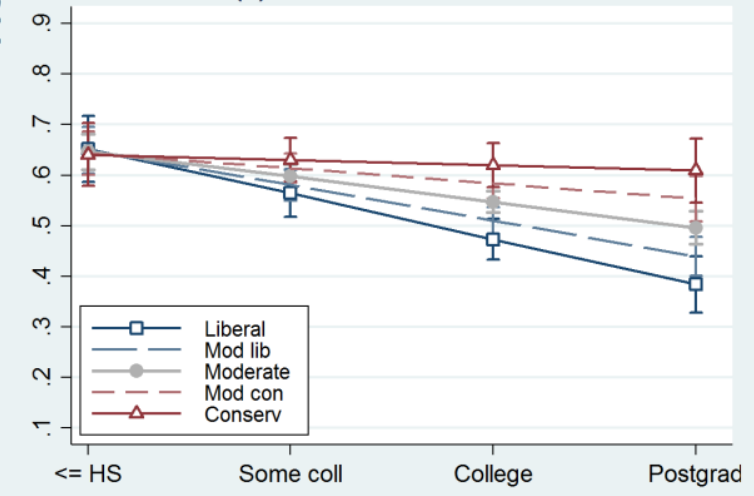

(b) Public radio news often

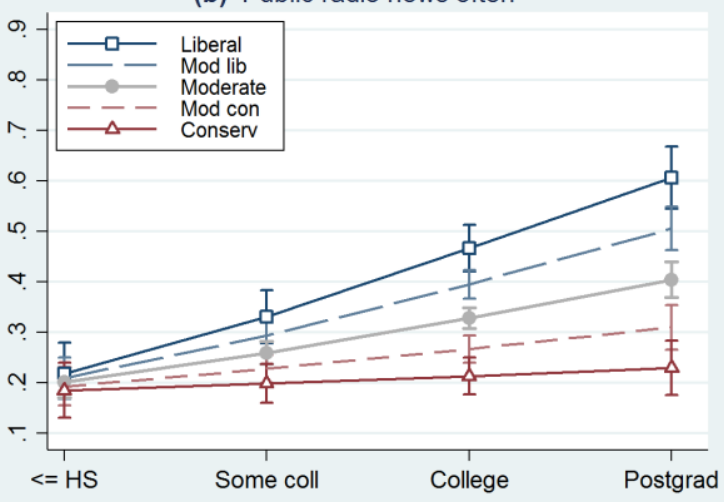

(d) Climate change human caused

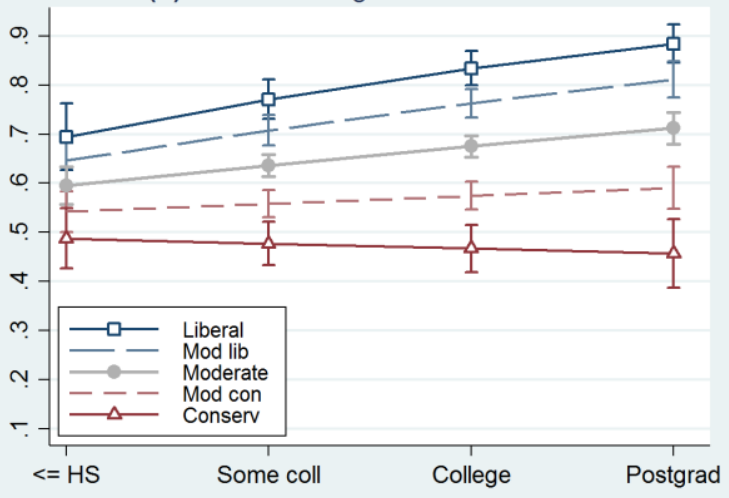

Figure 3. Viewership of information sources and belief in anthropogenic climate change by education across political ideologies.

Exogenous variables such as education and ideology influence climate beliefs directly, but also indirectly through their effects on media preferences. Information choice affects climate beliefs in turn, and with the directions that one might expect. Fox News viewership shows a negative effect on belief in human-caused climate change $(b=-0.748, p<0.001)$. Public radio listening ( $b=0.497, p<0.001)$ and local TV news watching $(b=0.322, p<0.01)$, on the other hand, each exhibit positive effects. That all three of our specific news media indicators show party, ideology, and educationxideology effects fits with selective exposure and biased assimilation interpretation of such interactions affecting climate change beliefs. More educated 
partisans tend to choose ideologically-aligned information sources. Similar patterns might reasonably be expected for other information sources (such as websites and talk radio) that were not tested here.

Scholars have proposed a number of alternative methods for estimating and testing indirect effects in logit and other nonlinear models. We applied the product-of-coefficients method described by Breen et al. (2013), which is computationally simple yet performs competitively in Monte Carlo evaluations. Results from these 24 additional coefficients and their tests are not listed in Table 2, but can be summarized as follows. Age has significant indirect effects on climate beliefs through all three media choices. Sex exhibits significant effects only through public radio and local TV preference. Party and ideology in comparison have significant indirect effects through the more ideologically-linked sources, Fox News and public radio. Both education and the education $\times$ ideology interaction show significant indirect effects through all three news sources. Thus, most of the path sequences that can be traced in Figure 2 correspond to statistically significant indirect effects. In all cases, these indirect effects have the expected signs.

The direct effects from all three news items also mean that ideology, education, and other background characteristics affect climate beliefs not just directly, but indirectly through media choices that further reinforce pre-existing beliefs. Furthermore, because news preferences also show independent effects even after adjusting for individual backgrounds, we can infer that news media content itself contributes to polarization. The analysis gives a cross-sectional view of the reinforcing spirals process through which political identity affects choice of information sources, and the content of those sources can reinforce and amplify divisions.

\section{Discussion}

Our data and analysis focus on climate change, a topic that has become so polarized that it behaves like a core indicator for political outlook alongside ideology and party (Kahan 2015). U.S. public perceptions of climate change are socially remarkable and globally important. The dynamics of selective exposure have acquired even greater prominence since we designed our research. With the 2016 presidential election campaign and subsequent developments, 'alternative facts' promulgated with political intent and targeted to ideologically-receptive audiences through their preferred media sources have become a major force in U.S. politics. Much as the 'climategate' hacking and edited release of scientists' emails in 2009 foreshadowed the hacking of Democratic National Committee emails in 2016, a long tradition of counterfactual assertions on climate change (Dunlap and McCright 2015) appears now to have foreshadowed a situation where counterfactual assertions about almost anything can be boosted to wide currency. The selective exposure process studied here with regard to climate change expanded dramatically to encompass many other topics.

More narrowly, our study contributes to the literature on polarization of climate change perceptions. We find evidence that political ideology and party predict climate change beliefs not just directly but indirectly, through exposure to politically-aligned information sources. The predictors of news media preferences resemble those for climate beliefs themselves, including the detail of similar educationxideology interactions. With such selection, news media will often help to confirm existing prejudices regarding climate change and many other topics. However, news media also have independent effects, net of their audience's background politics, which could amplify divisions. These findings connect several themes in the literature.

First, they depict processes of selective exposure and confirmation bias, especially among conservative audiences. Political party and ideology predict both Fox News and public radio 
preferences, but the Fox News preference is more strongly politicized - as shown by substantially larger party and ideology main effects, as well as a somewhat stronger education $\times$ ideology interaction. This interaction, visualized in Figure 3a, reverses the sign of education effects. Fox News preference rises with education among conservatives while declining with education among liberals. Public radio preference (Figure $3 b$ ) exhibits virtually no effect from education among conservatives, but a substantial positive effect among liberals. Regarding local TV news preference (Figure 3c), there is no positive effect from education among any of the ideological groups. Moderates as well as liberals with higher education become progressively less likely to watch local TV news.

The weak main effect from education on Fox News viewership, especially compared to other information choices, supports previous research suggesting conservatives are more likely to seek news media that support their predispositions. Studies of selective exposure (Sears and Freedman 1967, Feldman et al. 2014) sometimes depict this as a process equally prevalent on the left and right. However, observation of contemporary candidate and political media positions suggests that mainstream conservatives more often express opposition to core areas of science on topics ranging from climate change to evolution, the age of the Earth, or vaccines. Surveys confirm this impression of greater conservative distrust of science across a wider range of topics (Gauchat 2012, Nadelson et al. 2014, Hamilton and Saito 2015, Hamilton et al. 2015a, Nisbet et al. 2015).

The strong educationxideology effect on Fox News preference connects to the literature in other ways as well. Fox News viewers tend to be more politically homogenous compared to consumers of non-conservative news media, suggesting conservatives engage in motivated reasoning to identify sources that provide confirming information (Feldman et al. 2014). Conservative news media acts as an 'echo chamber' to reinforce predispositions (Feldman et al. 2012, 2014). Additionally, conservatives exhibit greater polarization when exposed to disconfirming information. Corner and colleagues' (2012) finding that biased assimilation can occur independently of attitude polarization supports this notion. Accounting for most of education's individual effect, the strong interaction effect between education and ideology in this study illustrates the impact of conservatism in selecting information sources. The reinforcing spirals framework effectively illustrates the cycle as background predictors influence news media choices that reinforce existing beliefs and promotes subsequent use (Feldman et al. 2014). In a nationwide study, almost $80 \%$ of Fox News viewers describe their political ideology as conservative and two-thirds identify as Republican (Saad 2013). In sum, Fox News provides conservatives with messaging that supports their political beliefs, an identity so influential it moderates differences in education.

We find that news media preferences are more directly predictive of climate change beliefs than education. Acceptance of anthropogenic climate change decreases with Fox News viewership, increases with public radio listenership, and increases also (but less steeply) with local TV viewership. However, because better-educated partisans more actively select compatible media sources, the indirect and total effects of education on climate beliefs are more complicated. For liberals, indirect effects add to and strengthen the total effect of education: Educated liberals are more likely to listen to public radio and less likely to watch Fox News, both of which (other things being equal) increase the probability of believing that humans are changing the climate. For conservatives on the other hand, a mix of positive and negative indirect effects through information sources tends to weaken the total effect of education so that political identity dominates. 
The link between conservative or liberal news media and climate change beliefs lends support to the elite cues hypothesis, a top-down aspect of biased assimilation. Previous research suggests that elite cues from prominent political leaders, those most influential in challenging expert opinion, are transmitted to the public through news media (Brulle et al. 2012, Darmofal 2005). While there are considerable differences between conservative and non-conservative media in how climate change is framed in reporting (Nisbet 2009, Feldman et al. 2012), framing can become ineffective on highly politicized issues (Zhou 2016). Partisan information sources are especially ripe environments for transmitting elite cues and supplying message frames that reinforce existing beliefs.

Much of the research on information and climate change perceptions cites cross-sectional nationally representative surveys (Hamilton 2008, Zhao 2009, 2011, Hamilton et al. 2012, Guber 2013, Feldman et al. 2014) or experimental designs (Hart and Nisbet 2011, Corner et al. 2012, McCright et al. 2013, Zhou 2016). By using the Granite State Poll we limit the nominal scope of this analysis to New Hampshire residents, but other studies making detailed U.S.-New Hampshire comparisons suggest the latter provides a close proxy on climate topics (e.g., Hamilton et al. 2015b, Hamilton 2016a, 2016b, 2017).

\section{Conclusion}

As one of the most polarizing issues in U.S. politics today, climate change presents a substantial challenge for science communication. News media play a central role that can either be constructive, exposing their audience to different perspectives and evidence-based information, or manipulative and divisive. Fox News and similar information sources have influenced public perceptions of this scientific topic just as they have of more clearly political issues in the United States. When people express high confidence in beliefs about science that contradict the scientific evidence, understanding how those beliefs developed and are maintained against contradictions becomes crucial. Communication processes such as selective exposure, elite cues, and reinforcing spirals allow biased information sources to amplify ideology-based differences, attenuating the potential for influence by outside experts and evidence. Survey data analysis provides a cross-sectional view of these processes, which are broadly reshaping American perceptions of reality. Similar processes undoubtedly occur in other countries too, but to variable degrees that should be a focus of new comparative research. Studies in the U.S. and elsewhere could help in finding escape routes from this cycle, not by confronting those deep in its grip, but by identifying groups and subtopics with less restricted sources, so that better evidence and science communication have a chance to get through.

\section{Acknowledgements}

Environmental and science questions on the Granite State Poll have been supported by the New Hampshire EPSCoR Ecosystems and Society project (NSF EPS-1101245), and the Carsey

School of Public Policy and the Sustainability Institute at the University of New Hampshire. Any opinions, findings, and conclusions or recommendations expressed in this material are those of the authors and do not necessarily reflect the views of the National Science Foundation. The Survey Center at University of New Hampshire conducted sampling and interviews. 


\section{References}

AAPOR. 2006. Standard Definitions: Final Disposition of Case Codes and Outcome Rates for Surveys. 4th ed. Lenexa, KS: American Association for Public Opinion Research.

Antonio, Robert J. and Brulle, Robert J., 2011. The unbearable lightness of politics: Climate change denial and political polarization. The Sociological Quarterly, 52 (2), 195-202. doi:10.1111/j.1533-8525.2011.01199.x

Bartlett, Bruce, 2013. The Decline of the Tea Party [online]. New York Times, 5 Nov. Available from: http://economix.blogs.nytimes.com/2013/11/05/the-decline-of-the-tea-party/

Borick, Christopher P. and Rabe, Barry G., 2010. A reason to believe: examining the factors that determine individual views on global warming. Social Science Quarterly, 91 (3), 777800. doi:10.1111/j.1540-6237.2010.00719.x

Boykoff, Maxwell T., 2007. From convergence to contention: United States mass media representations of anthropogenic climate change science. Transactions of the Institute of British Geographers, 32 (4), 477-489. doi:10.1111/j.1475-5661.2007.00270.x

Breen, Richard, Karlson, Kristian Bernt, and Holm, Anders, 2013. Total, direct, and indirect effects in logit and probit models. Sociological Methods and Research, 42 (2), 164-191. doi: 10.1177/0049124113494572

Brulle, Robert J., Carmichael, Jason, and Jenkins, J. Craig, 2012. Shifting public opinion on climate change: an empirical assessment of factors influencing concern over climate change in the U.S., 2002-2010. Climatic Change, 114 (2), 169-188. doi:10.1007/s10584012-0403-y

Carmichael, Jason T. and Brulle, Robert J., 2017. Elite cues, media coverage, and public concern: An integrated path analysis of public opinion on climate change, 2001-2013. Environmental Politics, 26 (2), 232-252. doi:10.1080/09644016.2016.1263433

Carmichael, Jason T., Brulle, Robert J., and Huxster, Joanna K. 2017. The great divide: Understanding the role of media and other drivers of the partisan divide in public concern over climate change in the USA, 2001-2014. Climatic Change, 141, 599-612. doi:10.1007/s10584-017-1908-1

Corner, Adam, Whitmarsh, Lorranie, and Xenias, Dimitrios, 2012. Uncertainty, scepticism and attitudes towards climate change: biased assimilation and attitude polarisation. Climatic Change, 114 (3-4), 463-478. doi:10.1007/s10584-012-0424-6

Darmofal, David, 2005. Elite cues and citizen disagreement with expert opinion. Political Research Quarterly, 58 (3), 381-395. doi:10.1177/106591290505800302

Davenport, Coral, 2016. Climate change divide bursts to forefront in presidential campaign [online]. New York Times, 1 Aug. Available from: http://www.nytimes.com/2016/08/02/us/politics/climate-change-divide-bursts-toforefront-in-presidentialcampaign.html?rref=collection\%2Ftimestopic\%2FGlobal\%20Warming\&_r=0

Drummond, Caitlin and Fischhoff, Baruch, 2017. Individuals with greater science literacy and education have more polarized beliefs on controversial science topics. Proceedings of the National Academy of Sciences. doi: 10.1073/pnas.1704882114

Dunlap, Riley E. and McCright, Aaron M., 2015. Challenging climate change: The denial countermovement. In: R.E. Dunlap and R.J. Brulle, eds. Climate Change and Society: Sociological Perspectives. New York: Oxford University Press, 300-332. 
Dunlap, Riley E., McCright, Aaron M., and Yarosh, Jerrod H., 2016. The political divide on climate change: partisan polarization widens in the U.S. Environment: Science and Policy for Sustainable Development, 58 (5), 4-23. doi:10.1080/00139157.2016.1208995

Ehret, Phillip J., Sparks, Aaron and Sherman, David. 2017. Support for environmental protection: an integration of ideological-consistency and information-deficit models. Environmental Politics, 26 (2), 53-277. doi:10.1080/09644016.2016.1256960

Feldman, Lauren, et al., 2012. Climate on cable: the nature and impact of global warming coverage on Fox News, CNN, and MSNBC. The International Journal of Press/Politics, 17 (1), 3-31. doi:10.1177/1940161211425410

Feldman, Lauren, et al., 2014. The mutual reinforcement of media selectivity and effects: testing the reinforcing spirals framework in the context of global warming. Journal of Communication, 64, 590-611. doi:10.1111/jcom.12108

Gauchat, Gordon, 2012. Politicization of science in the public sphere: a study of public trust in the United States, 1974 to 2010. American Sociological Review, 77 (2), 167-187. doi:10.1177/0003122412438225

Guber, Debora Lynn, 2013. A cooling climate for change? Party polarization and the politics of global warming. American Behavioral Scientist, 57 (1), 93-115. doi:10.1177/0002764212463361

Hamilton, Lawrence C., 2008. Who cares about polar regions? Results from a survey of U.S. public opinion. Arctic, Antarctic, and Alpine Research, 40 (4), 671-678. doi:10.1657/1523-0430(07-105)[HAMILTON]2.0.CO;2

Hamilton, Lawrence C., 2011. Education, politics and opinions about climate change evidence for interaction effects. Climatic Change, 104 (2), 231-242. doi:10.1007/s10584-0109957-8

Hamilton, Lawrence C., 2014. Do you trust scientists about the environment? News media sources and politics affect New Hampshire resident views. Regional Issue Brief No. 40. Durham, NH: Carsey School of Public Policy, University of New Hampshire. http://scholars.unh.edu/carsey/213/

Hamilton, Lawrence C., 2016a. Public awareness of the scientific consensus on climate. Sage Open. doi:10.1177/2158244016676296

Hamilton, Lawrence C., 2016b. Where is the North Pole? An election-year survey on global change. National Issue Brief No. 107. Durham, NH: Carsey School of Public Policy, University of New Hampshire. http://scholars.unh.edu/carsey/285/

Hamilton, Lawrence C. 2017. Public acceptance of human-caused climate change is gradually rising. Durham, NH: Carsey School of Public Policy. http://scholars.unh.edu/carsey/322/

Hamilton, Lawrence C. and Keim, Barry D., 2009. Regional variation in perceptions about climate change. International Journal of Climatology, 29 (15), 2348-2352. doi: $10.1002 /$ joc. 1930

Hamilton, Lawrence C. and Safford, Thomas G., 2015. Environmental views from the coast: public concern about local to global marine issues. Society and Natural Resources, 28 (1), 57-74. doi:10.1080/08941920.2014.933926

Hamilton, Lawrence C. and Saito, Kei, 2015. A four-party view of US environmental concern. Environmental Politics, 24 (2), 212-227. doi:10.1080/09644016.2014.976485

Hamilton, Lawrence C., Colocousis, Chris R., and Duncan, Cynthia M., 2010. Place effects on environmental views. Rural Sociology, 75 (2), 326-347. doi:10.1111/j.1549-

0831.2010.00013.x 
Hamilton, Lawrence C., Cutler, Matthew J., and Schaefer, Andrew, 2012. Public knowledge and concern about polar-region warming. Polar Geography, 35 (2), 155-168. doi:10.1080/1088937X.2012.684155

Hamilton, Lawrence C., Hartter, Joel, and Saito, Kei, 2015a. Trust in scientists on climate change and vaccines. Sage Open, 5 (3). doi:10.1177/2158244015602752

Hamilton, Lawrence C., et al., 2015b. Tracking public beliefs about anthropogenic climate change. PloS One, 10 (9). doi:10.1371/journal.pone.0138208

Hart, P. Sol and Nisbet, Erik C., 2011. Boomerang effects in science communication: how motivated reasoning and identity cues amplify opinion polarization about climate mitigation policies. Communication Research, 1-23. doi:10.1177/0093650211416646

Jacques, Peter J., Dunlap, Riley E., and Freeman, Mark, 2008. The organisation of denial: conservative think tanks and environmental scepticism. Environmental Politics, 17 (3), 349-385. doi:10.1080/09644010802055576

Jasny, Lorien, Waggle, Joseph, and Fisher, Dana R., 2015. An empirical examination of echo chambers in US climate policy networks. Nature Climate Change, 5 (8), 782-786. doi:10.1038/nclimate2666

Kahan, Dan M., 2015. Climate-science communication and the measurement problem. Political Psychology, 36 (S1), 1-43. doi:10.1111/pops.12244

Kahan, Dan M., Jenkins-Smith, Hank, and Braman, Donald, 2011. Cultural cognition of scientific consensus. Journal of Risk Research, 14 (2), 147-174. doi:10.1080/13669877.2010.511246

Kahan, Dan M., et al., 2012. The polarizing impact of science literacy and numeracy on perceived climate change risks. Nature Climate Change, 2 (10), 732-735. doi:10.1038/NCLIMATE1547

Kim, Sung Eun and Urpelainen, Johannes, 2018. Environmental public opinion in U.S. states, 1973-2012. Environmental Politics, 27 (1), 89-114. doi:10.1080/09644016.2017.1362720

Krosnick, Jon A., and MacInnis, Bo, 2010. Frequent viewers of Fox News are less likely to accept scientists' views of global warming. Report. Stanford, CA: Woods Institute for the Environment, Stanford University.

Layman, Geoffrey C., Carsey, Thomas M., and Horowitz, Juliana Menasce, 2006. Party polarization in American politics: characteristics, causes, and consequences. Annual Review of Political Science, 9 (1), 83-110. doi:10.1146/annurev.polisci.9.070204.105138

Lee, Tien Ming, et al., 2015. Predictors of public climate change awareness and risk perception around the world. Nature Climate Change, 5 (11), 1014-1020. doi:10.1038/nclimate2728

Lipton, Eric and Steinhauer, Jennifer, 2015. 'Fire Paul Ryan'? Rebel PACs hit Republicans, and it pays [online]. New York Times, 23 Oct. Available from: http://www.nytimes.com/2015/10/24/us/politics/conservative-pacs-turn-attack-on-gopleaders-into-fund-raising-tool.html?_r=2

Lord, Charles G., Ross, Lee, and Lepper, Mark R., 1979. Biased assimilation and attitude polarization: The effects of prior theories on subsequently considered evidence. Journal of Personality and Social Psychology, 37 (11), 2098-2109. doi:10.1037/00223514.37.11.2098

McCright, Aaron M., 2011. Political orientation moderates Americans' beliefs and concern about climate change. Climatic Change, 104 (2), 243-253. doi:10.1007/s10584-010-9946-y 
McCright, Aaron M. and Dunlap, Riley E., 2010. Anti-reflexivity: the American conservative movement's success in undermining climate science and policy. Theory, Culture and Society, 27 (2-3), 100-133. doi:10.1177/0263276409356001

McCright, Aaron M. and Dunlap, Riley E., 2011. The politicization of climate change and polarization in the American public's views of global warming, 2001-2010. The Sociological Quarterly, 52 (2), 155-194. doi:10.1111/j.1533-8525.2011.01198.x

McCright, Aaron M., Dunlap, Riley E., and Xiao, Cenyang, 2014. Increasing influence of party identification on perceived scientific agreement and support for government action on climate change in the United States, 2006-12. Weather, Climate and Society, 6 (2), 194 201. doi:10.1175/WCAS-D-13-00058.1

McCright, Aaron M., et al., 2013. The influence of political ideology on trust in science. Environmental Research Letters, 8 (4), 044029-21009. doi:10.1088/17489326/8/4/044029

Munro, Geoffrey D. and Ditto, Peter H., 1997. Biased assimilation, attitude polarization, and affect in reactions to stereotype-relevant scientific information. Personality and Social Psychology Bulletin, 23 (6), 636-653. doi:10.1177/0146167297236007

Myers, Teresa A., et al., 2012. A public health frame arouses hopeful emotions about climate change. Climatic Change, 113 (3-4), 1105-1112. doi:10.1007/s10584-012-0513-6

Nadelson, Louis, et al., 2014. I just don't trust them: the development and validation of an assessment instrument to measure trust in science and scientists. School Science and Mathematics, 114 (2), 76-86. doi:10.1111/ssm.12051

NASA, 2016. NASA, NOAA Analyses reveal record-shattering global warm temperatures in 2015. New York: Goddard Institute for Space Studies.

Nisbet, Matthew C., 2009. Communicating climate change: why frames matter for public engagement. Environment, 51 (2), 14-23. doi:10.3200/ENVT.51.2.12-23

Nisbet, Erik C., Cooper, Kathryn E., and Garrett, R. Kelly, 2015. The partisan brain: How dissonant science messages lead conservatives and liberals to (dis)trust science. The Annals of the American Academy of Political and Social Science, 658 (1), 36-66. doi:10.1177/0002716214555474

Saad, Lydia, 2013. TV Is Americans' main source of news. Gallup. Available from: http://www.gallup.com/poll/163412/americans-main-source-news.aspx [Accessed 22 August 2015].

Saad, Lydia and Jones, Jeffrey M., 2016. U.S. concern about global warming at eight-year high. Gallup. Available from: http://www.gallup.com/poll/190010/concern-global-warmingeight-year-high.aspx [Accessed 5 September 2016].

Sears, David O., and Freedman, Jonathan L., 1967. Selective exposure to information: A critical review. Public Opinion Quarterly, 31 (2), 194-213. doi:10.1086/267513

Shao, Wanyun, 2016. Weather, climate, politics, or God? Determinants of American public opinions toward global warming. Environmental Politics, 26 (1), 71-96. doi:10.1080/09644016.2016.1223190

Shao, Wanyun, et al., 2014. Weather, climate, and the economy: explaining risk perceptions of global warming, 2001-10. American Meteorological Society, 6 (1), 119-134. doi:10.1175/WCAS-D-13-00029.1

Slater, Michael D., 2007. The mutual influence of media selectivity and media effects and their impact on individual behavior and social identity. Communication Theory, 17 (3), 281303. doi:10.1111/j.1468-2885.2007.00296.x 
Stroud, Natalie Jomini, 2011. Niche news: The politics of news choice. Oxford University Press on Demand.

Taber, Charles S. and Lodge, Milton, 2006. Motivated skepticism in the evaluation of political beliefs. American Journal of Political Science, 50 (3), 755-769. doi:10.1111/j.15405907.2006.00214.x

Van Liere, Kent D. and Dunlap, Riley E., 1980. The social bases of environmental concern: a review of hypotheses, explanations and empirical evidence. Public Opinion Quarterly, 44 (2), 181-197. doi:10.1086/268583

Wood, B. Dan and Vedlitz, Arnold, 2007. Issue definition, information processing, and the politics of global warming. American Journal of Political Science, 51 (3), 552-568. doi:10.1111/j.1540-5907.2007.00267.x

Zhao, Xiaoquan, 2009. Media use and global warming perceptions: a snapshot of the reinforcing spirals. Communication Research, 36 (5), 698-723. doi:10.1177/0093650209338911

Zhao, Xiaoquan, et al., 2011. Attention to science/environment news positively predicts and attention to political news negatively predicts global warming risk perceptions and policy support. Journal of Communication, 61 (4), 713-731. doi:10.1111/j.14602466.2011.01563.x

Zhou, Jack, 2016. Boomerangs versus javelins: how polarization constrains communication on climate change. Environmental Politics, 25 (5), 788-811. doi:10.1080/09644016.2016.1166602 